\title{
Analysis of the soil arching effect under pile- soil coupling for a landslide in the Three Gorges Reservoir Area based on three- dimensional numerical simulation
}

\author{
Baoqin LIAN \\ Department Department of Building Engineering \\ Guangzhou City Construction College, Guangdong \\ Guangzhou, China \\ e-mail: 328602223@qq.com \\ Xingang Wang* \\ State Key Laboratory of Continental Dynamics \\ Northwest University \\ Xi'an, China \\ e-mail: wangxingang4202@163.com
}

\author{
Jianhua Li \\ Department Department of Building Engineering \\ Guangzhou City Construction College, Guangdong \\ Guangzhou, China \\ e-mail:914108739@qq.com
}

\begin{abstract}
Deflection of stress direction occurs near antislide piles, forming obvious soil arches with adjacent piles as springers and creating the "soil arching effect". Based on the stress conditions for anti-slide piles, a mechanical analysis is conducted on the soil arching effect, and three rational equations are concluded, namely, the arch axis equation, the soil arch thickness equation, and the theoretical equation of soil arch thickness along the sliding direction. Combined with one landslide in the three gorges reservoir area, numerical analysis model is established, the landslide displacement and shear stress calculation results show that the pile has obvious slip resistance effect, the piles and soil coupling to prevent sliding. Three-dimensional numerical analysis was carried out on the pile, the intuitive "soil arching effect" be found from the anti-slide pile and soil. The soil arch thickness and height of anti-slide pile can be determined according to the soil sliding thrust and the theoretical formula that combines three dimensional numerical analysis for the soil arch effect, which can provide references for the anti-slide pile design and achieve the goal of safe and economic to prevention and control the landslide.
\end{abstract}

Keywords- landslide; soil arching effect; anti-slide piles; numerical calculation; the coupling of piles and soil;

\section{INTRODUCTION}

In slope protection engineering, anti-slide piles, for their strong anti-slide performance, flexible pile position and wide scope of application, have become one of the most widely used deep anti-slide retaining measures at present[1]. Under lateral load, anti-slide piles generate the so-called "soil arching effect" as they interact with the soil, which is an important basis for investigating the reinforcement mechanism and design theory regarding anti-slide piles ${ }^{[1 \sim 2]}$. Soil arching was first proposed by Terzaghi based on trap door experiment ${ }^{[3]}$. Later, a number of scholars began to vigorously study the soil arching effect. Their research outcomes are mainly divided into three categories: (1) theoretical analysis ${ }^{[4 \sim 8]}$, mainly involving the establishment of relevant mathematical physics equation and investigation of the relationship between soil arching effect of anti-slide piles and pile spacing; (2) numerical simulation ${ }^{[9 \sim 14]}$, mainly involving the simulation of pile-soil interaction by use of numerical analysis software; (3) experimental study ${ }^{[15]}$, mainly involving the study of pile-soil interaction by laboratory experiment.

The landslide sliding force is in non-horizontal spatial distribution, while the direction of stress near anti-slide piles deflects, forming soil arches with adjacent piles as springers. Among the references, little consideration is given to the soil arching effect under pile-soil interaction in three-dimensional status ${ }^{[4 \sim 15]}$. In this paper, a landslide in the Three Gorges Reservoir Area was chosen as an example to conduct a three-dimensional numerical analysis on the soil arching effect under pile-soil interaction by use of the three-dimensional numerical analysis software FLAC3D.

\section{MECHANICAL ANALYSIS OF SOIL ARCHING EFFECT}

Soil arches are formed under the effect of landslide sliding force, further forming arched stress zones, similar to statically determinate arches in structural mechanics; soil arch of unit thickness was taken for stress analysis (see Fig .1. $)^{[9 \sim 10]}$.

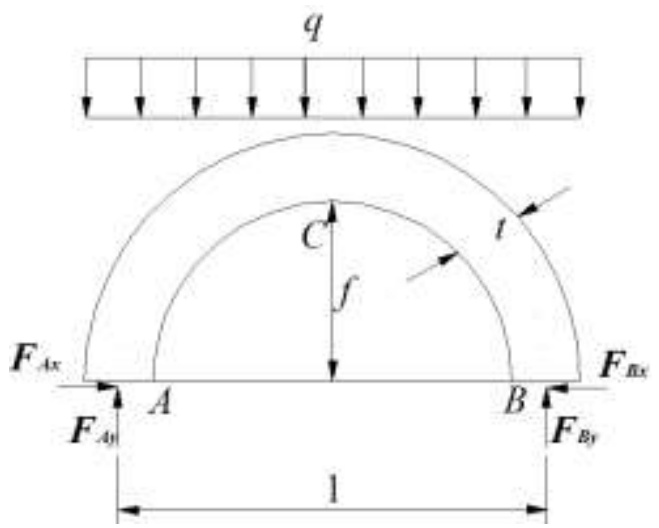

Figure 1. Mechanics calculation chart of soil arch 


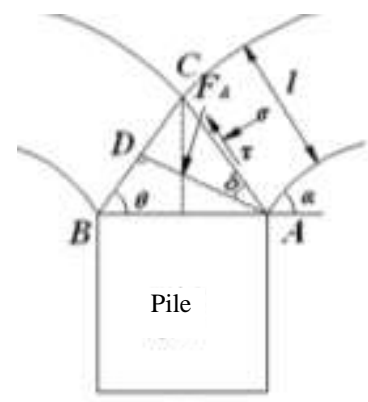

(a)

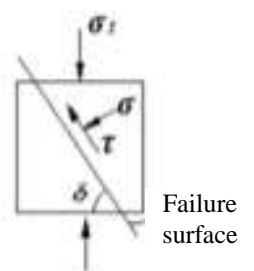

(b)
Figure 2. Mechanical analysis of soil behind piles

In Fig .1, q represents landslide sliding force; 1 represents soil arch span, i.e., pile spacing; $t$ represents soil arch thickness; f represents soil arch height; $F_{A x}, F_{A y}, F_{B x}$ and $F_{B y}$ are respectively horizontal reacting force and vertical reacting force at springers. A rational arch axis equation can be obtained, which is written as

$$
y=\frac{4 f}{l^{2}}(l-x) x
$$

Stress inside soil arches will form a compression zone; if the force applied to the soil in the compression zone is greater than the soil shear strength, failure of the entire soil arch will take place. Fig .2 shows the mechanical analysis of soil arch height and thickness. In Fig .2, AB=b is backside thickness of pile; $A D=t$ is soil arch thickness; $A C$ is length of failure surface; $\delta$ is angle between failure surface and maximum principal stress surface; $\sigma$ and $\tau$ are respectively normal stress and shear stress on the failure surface; FA is resultant force at springers.

$$
\begin{array}{r}
\delta=45^{\circ}+\frac{\varphi}{2} \\
\mathrm{~F}_{\mathrm{A}}=\sqrt{\mathrm{F}_{\mathrm{Ax}}^{2}+\mathrm{F}_{\mathrm{Ay}}^{2}}=\frac{q l}{8 f} \sqrt{16 f^{2}+l^{2}} \\
t=b \sin \theta=\frac{b \cos \delta}{2 \cos \theta} \\
\theta=135^{\circ}+\frac{\varphi}{2}-\alpha \\
t=\frac{b \cos \left(45^{\circ}+\frac{\varphi}{2}\right)}{2 \cos \left(135^{\circ}+\frac{\varphi}{2}-\alpha\right)}
\end{array}
$$

Substituting Eq. (1)-(5) into

$$
\tan \alpha=\frac{4 f}{l} \quad \alpha=\arctan \frac{4 f}{l} \text { gives: }
$$

$$
\tan \alpha=4 \tan \delta=4 \tan \left(45^{\circ}+\frac{\varphi}{2}\right)
$$

Substituting Eq. (7) into Eq. (6) gives the soil arch thickness along the sliding direction:

$$
\begin{aligned}
t & =\frac{b \cos \left(45^{\circ}+\frac{\varphi}{2}\right)}{2 \cos \left(135^{\circ}+\frac{\varphi}{2}-\alpha\right)} \\
& =\frac{b \cos \left(45^{\circ}+\frac{\varphi}{2}\right)}{2 \cos \left(45^{\circ}+\frac{\varphi}{2}\right) \sin \alpha-\sin \left(45^{\circ}+\frac{\varphi}{2}\right) \cos \alpha} \\
= & \frac{b \cos \left(45^{\circ}+\frac{\varphi}{2}\right)}{6 \cos \left(45^{\circ}+\frac{\varphi}{2}\right) \cos \alpha} \\
= & \frac{b}{6} \cot \left(45^{\circ}+\frac{\varphi}{2}\right) \frac{1}{\cos \alpha}
\end{aligned}
$$

\section{ENGINEERING EXAMPLE AND THREE-DIMENSIONAL NUMERICAL MODEL}

In the three-dimensional numerical model, Majiagou Landslide I in the Three Gorges Reservoir Area was taken as example; the medial axis profile of Landslide I (see Fig .3) was chosen to establish the numerical model. At present, this landslide has been controlled with anti-slide piles. Considering the pile-soil effect and pile-pile effect, four completed piles (length: $18 \mathrm{~m}$; cross-section: $2 \mathrm{~m} \times 3 \mathrm{~m}$; pile spacing: $5 \mathrm{~m}$ ) in the middle of the landslide were chosen for three-dimensional analysis of the anti-sliding effect of anti-slide piles and the soil arching effect. ANSYS pretreatment was adopted for the model; densified meshing was carried out partially in the pile and soil survey zone and landslide-slip zone; FLAC3D software was introduced; the model had 117,544 units and 118,917 nodes in total (see Fig .4). The pile side friction was simulated through the interface set between the pile side surface and the soil layer[16]; an interface was also set between the pile tip and the soil layer; the "guide-in guideout method" was used to establish the interface model (see Fig .4).

The undersurface and left and right sides of the computational model were fixed and its top surface was free; the front and back sides of the model were also fixed. The mechanical parameter of each medium in the pile-soil model could affect the accuracy of calculated results; Mohr-Coulomb model was adopted for rock and soil mass and elastic model for anti-slide piles; parameters were obtained by laboratory experiments. 


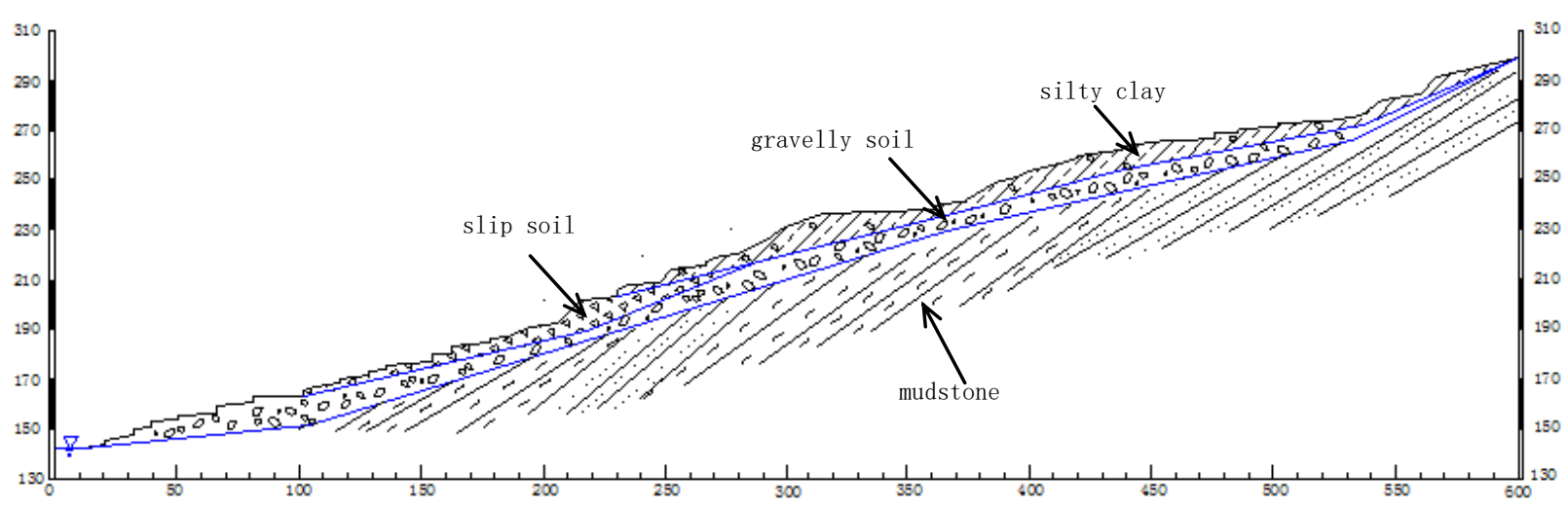

Figure 3. Engineering geologic profile of Landslide I

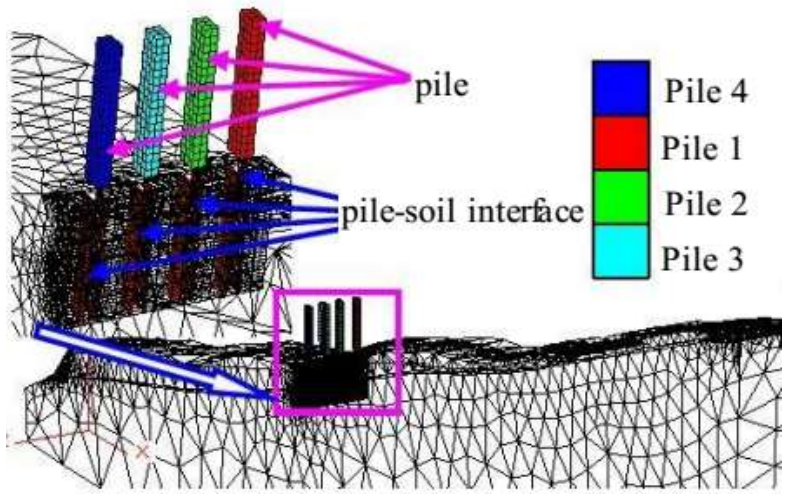

Figure 4. Pile-soil's interface in the model

TABLE I. CALCULATION PARAMETERS OF MODEL

\begin{tabular}{cccccc}
\hline Name & $\begin{array}{c}\text { density } \\
(\mathrm{g} / \mathrm{cm} 3)\end{array}$ & $\begin{array}{c}\text { Cohesion } \\
(\mathrm{MPa})\end{array}$ & $\begin{array}{c}\text { Angle of } \\
\text { internal } \\
\text { friction } \\
\left({ }^{\circ}\right)\end{array}$ & $\begin{array}{c}\text { bulk } \\
\text { modulus } \\
(\mathrm{GPa})\end{array}$ & $\begin{array}{c}\text { Shear } \\
\text { modulus } \\
(\mathrm{GPa})\end{array}$ \\
\hline $\begin{array}{c}\text { silty clay } \\
\text { slip soil }\end{array}$ & 2.1 & 0.052 & 33 & 0.011 & 0.0083 \\
$\begin{array}{c}\text { grave11y } \\
\text { soil }\end{array}$ & 2.4 & 0.018 & 14.5 & 0.0083 & 0.0018 \\
$\begin{array}{c}\text { mudstone } \\
\text { anti-slide } \\
\text { pile }\end{array}$ & 2.4 & 2.16 & 32.3 & 1.55 & 1.16 \\
\hline
\end{tabular}

\section{ANALYSIS OF CALCULATED RESULTS}

After numerical calculation, a series of sections were taken to conduct a three-dimensional analysis of the soil arching effect. The elevation of pile top is $104 \mathrm{~m}$; the results of several experiments show that the soil arching effect of shear force is obvious from the elevation of $97.5 \mathrm{~m}$ (Y-axis), i.e., $6.5 \mathrm{~m}$ away from the pile top (see Fig .5 a h).

For the section $6.5 \mathrm{~m}$ below the pile top (Fig .5-a), the map of shear stress of pile side soil shows arches looking like "round-backed armchairs"; the friction between pile side soil and pile causes obstruction again the soil, which results in deflection of shear stress trajectory and thus forms shear stress arches on the pile side and wide-angle layered stress arches behind the piles. For the sections 7$7.5 \mathrm{~m}$ below the pile top (Fig $.5 \mathrm{~b} \sim \mathrm{c}$ ), there are obvious layered shear stress arches behind each pile; the arch angles tend to be steep; the "saddle-like" area enlarges; there is an obvious shear stress compression zone behind each pile, and the compression zone gradually enlarges. For the sections $8-9 \mathrm{~m}$ below the pile top (Fig .5c f), the "saddle-like" stress arch area gradually reduces, and the value of shear stress in the compression zone behind each pile increases up to $0.26 \mathrm{MPa}$. For the sections $9-11 \mathrm{~m}$ below the pile top (Fig .5 g h), the compression zone behind each pile enlarges, and the value of shear stress in the compression zone behind each pile increases up to $0.3 \mathrm{MPa}$; stress arches between piles gradually disappear.

The arch thickness and height can be determined according to the landslide sliding force and Eq. (1)-(8) with combination of numerical simulation analysis of sectional diagrams. Shear stress arches behind the piles are $6.5-9.5 \mathrm{~m}$ away from the pile top (Fig .5 a-g); principal stress arches behind the piles are $7-9.5 \mathrm{~m}$ away from the pile stop (Fig .5 d-g). The pile-soil stress changes at the position $9 \mathrm{~m}$ away from the pile top; the soil around pile bears partial downslide stress of the landslide.

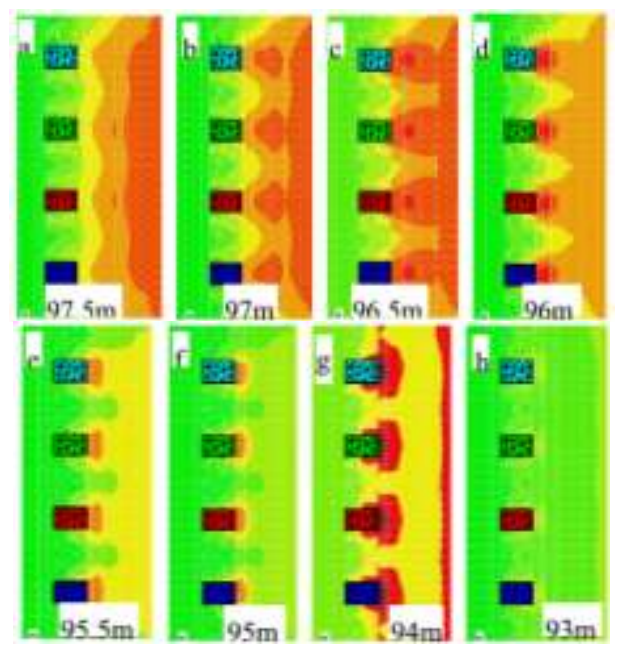

Figure 5. Section of a-h shear stress

\section{CONCLUSION}

Based on the stress conditions for anti-slide piles, a mechanical analysis was conducted on the soil arching effect, and three rational equations were concluded, namely, the arch axis equation, the soil arch thickness 
equation, and the theoretical equation of soil arch thickness along the sliding direction.

Taking a landslide in the Three Gorges Reservoir Area as an example, a numerical analysis model was established for computational analysis after anti-slide piles were constructed on the landslide. The calculated results show that the anti-slide piles have an obvious slide resistance effect; the anti-slide piles and the soil behind the piles play a role in preventing sliding of the landslide; the pile-soil "coupling" can prevent sliding.

When considering the model for computing the working conditions of anti-slide piles, a series of horizontal sections below the tops of anti-slide piles were chosen for three-dimensional numerical analysis of the soil arching effect. In the sectional diagrams of shear force, it is found that the anti-slide piles and the soil around pile all have visible "soil arching effect".

In practical engineering construction design, the soil arch thickness and height of anti-slide piles can be determined according to the landslide sliding force and the theoretical equation with combination of numerical simulation analysis of sectional diagrams, thus to optimize the design of anti-slide piles and achieve the goal of safe and economic prevention and control of landslide.

\section{ACKNOWLEDGMENT}

This study is partially supported by the National Natural Science Foundation of China (No. 41302219)

\section{REFERENCES}

[1] LI Shao-jun,CHEN Jing,LIAN Cao.Mechanical model of soil arch for interaction of piles and slope and problem of pile spacing[J].Rock and Soil Mechanics, 2010,31(5): 1352-1358. (in Chinese).

[2] FENG Wen-juan,JU Xiao-dong.Design method for anti-slide piles based on FLAC3D[J].Journal of Geotechnical Engineering,2011,33(supp2): 256-259.

[3] TERZAGHI K. Theoretical soil mechanics[M]. New Youk: JohnWiley\&Sons, 1943.
[4] OSSCHER B, PETER J, GRAY, DONALD H. Soil arching in sandy slopes[J]. Journal of Geotechnical Engineering, 1986 112(6): $626-645$.

[5] ITO T, MATSUI T, HONG W P. Extended design method for multi-row stabilizing piles against landslide[J]. Soils and Foundations, 1982, 22(1): 1-13.

[6] HASSIOTIS S, CHAMEAU J L, GUNARATNE M. Design method for stabilization of slopes with piles[J]. Journal of Geotechnical and Geoenvironmental Engineering, 1997, 123(4): $314-323$.

[7] ZHAO Ming-hua, LIAO Bin-bin, LIU Si-si. Calculation of antislide piles spacing based on soil arching effect[J]. Rock and Soil Mechanics, 2010, 31(4): 1211-1216.

[8] WU Ming, PENG Jianbing, XU Ping, et al. Study on earth pressure against rigid retaining walls considering soil arching effects[J]. Engineering Mechanics, 2011, 28(11) : 89-96.(in Chinese)

[9] CAI F, UGAI K. Numerical analysis of the stability of a slope reinforced with piles[J]. Soils and Foundations, 2000, 40(1): $73-$

[10] LIANG R, ZENG S. Numerical study of soil arching mechanism in drilled shafts for slope stabilization[J]. Soils and Foundations, 2002, 42(2): $83-92$.

[11] WEI W B, CHENG Y M. Strength reduction analysis for slope reinforced with one row of piles[J]. Computers and Geotechnics, 2009, 36(7): 1176-1185

[12] DANIEL PRADEL, JASON GARNER, ANNIE ON LEI KWOK Design of drilled shafts to enhance slope stability[C]//Proceedings of 2010 Earth Retention Conference. Los Angeles: [s. n.], 2010 $920-927$.

[13] KOURKOULIS R, GELAGOTI F, ANASTASOPOULOS I, et al Slope stabilizing piles and pile-groups: parametric study and design insights[J].Journal of Geotechnical and Geoenvironmental Engineering,2011,137(7).

[14] WANG Xingang, HU Bin, LIAN Baoqin, et al. 3D Analysis of Interaction Of Landslide And Anti-Slide Pile System Under Sudden Change Of Reservoir water Level [J]. Chinese Journal of Rock Mechanics and Engineering, 2013, 32(12): 2439-2446.

[15] GAO Chang-sheng, WEI Ru-long, CHEN Sheng-shui. Centrifugal model tests ondeformation of slopes reinforced with piles[J].Chinese Journal of Geotechnical Engineering, 2009, 31(1): 145-148.

[16] Chen Yuming,Xu Dingping. FLAC/FLAC3D Foundation and engineering examples [M]. China Water Conservancy and Hydropower Press, 2008 